\title{
America's deadly flirtation with antiscience and the medical freedom movement
}

\author{
Peter J. Hotez $z^{1,2,3,4,5}$ \\ 'Department of Pediatrics and Department of Molecular Virology \& Microbiology, Texas Children's Center for Vaccine Development, Baylor College of Medicine, Houston, Texas, USA. 2Department of Biology, \\ Baylor University, Waco, Texas, USA. ${ }^{3}$ Hagler Institute for Advanced Study, Texas A\&M University, College Station, Texas, USA. ${ }^{4}$ James A. Baker III Institute for Public Policy, Rice University, Houston, Texas, \\ USA. ${ }^{5}$ Scowcroft Institute of International Affairs, Bush School of Government and Public Service, Texas A\&M University, College Station, Texas, USA.
}

$\mathbf{T}_{1}$ he initial United States government response to the coronavirus disease 2019 (COVID-19) pandemic was marked by a frequent disconnect between government policies and the recommendations of scientific experts. A disinformation campaign from the Trump White House convinced many Americans that COVID-19 injuries and its death toll were exaggerated, leading many to ignore public health recommendations (1). Those who dismissed the severity of COVID-19 were more likely to shun face masks and ignore recommendations to socially distance from non-household members (2). Such individuals were more likely Republicans than Democrats by a wide margin (2), and under a flag of health or medical freedom, an outright defiance of masks and social distancing came to symbolize allegiance to President Trump (1). This contributed to the rampant spread of severe acute respiratory syndrome coronavirus 2 (SARSCoV-2) infections, which have taken the lives of one-half million Americans (1). Misguided ideologies from populist regimes in Brazil, Mexico, Nicaragua, Philippines, and Tanzania bear varying degrees of resemblance to health freedom and contribute to the global COVID-19 death toll (3). Here, I explore the anti-science movement in America, emphasizing our unique historical connections to health and medical freedom.

\section{Origins of health freedom in America}

Health freedom, also referred to as medical freedom, represents a longstanding and pervasive belief system in American life. Its tenets espouse an aversion to government interference in personal or family health choices, often coupled to the counter promotion of a spectacular or miracle cure. The concept is almost as old as the nation itself, although the newest iteration of health freedom defies vaccinations and federal or state public health interventions directed at COVID-19.

Beliefs in the individual rights for therapeutic choices harken back to the early American colonies and were further amplified in the 19th century (4). Front and center were the campaigns of Samuel Thompson (1769-1843) who created a system that listed six leading botanical treatments requiring no medical training to administer (5). Indeed, Thompson often mocked the existing medical establishment, and his followers were successful in repealing medical licensing laws (5). It is also interesting to note that both Thompson and Dr. Benjamin Rush, possibly the most influential physician in Colonial America, were staunch proponents of medical freedom, and there is a record of a celebrated meeting between the two (4). One consequence is that medical freedom rose to prominence during a 30-year period prior to the Civil War. The US essentially dissolved regulatory oversight in medical licensing (4). Although new requirements were gradually reintroduced in the post-war period, a subsequent wave of health freedom activities at the turn of the 20th century, including the formation of a National League for Medical Freedom, often worked to undermine regulations governing medical

Conflict of interest: PJH holds patents on vaccines for several poverty-related diseases and neglected tropical diseases, including hookworm infection, schistosomiasis, and Chagas disease (5,527,937; 5,753,787; 7,303,752 B2; 12/492,734; 61/077,256; PCT-20100701/0.20.5.18; PCT-61448231). He is an inventor on a COVID-19 vaccine technology owned by Baylor College of Medicine, recently licensed nonexclusively to Biological E Ltd. PJH is the author of the books Vaccines Did Not Cause Rachel's Autism: My Journey as a Vaccine Scientist, Pediatrician, and Autism Dad and Preventing the Next Pandemic: Vaccine Diplomacy in a Time of Anti-Science, both published by Johns Hopkins University Press.

Copyright: ( 2021 , American Society for Clinical Investigation.

Reference information: / Clin Invest. 2021;131(7):e149072. https://doi.org/10.1172/JCl149072.

practice $(4,6)$. The National League, for instance, became an umbrella organization for supporting "Homeopaths, the Eclectics, the Osteopaths, the Christian Scientists and other schools of Healing (e.g., ayurveda, chiropractic, faith healing, herbal folk medicine, naturopathy), the members of the AntiCompulsory Vaccination League and the Anti-Vivesection Society" (6).

Ultimately, in both the 19th and 20th centuries, the organizations espousing health freedom alternated with stringent oversight in an ebb and flow rhythm. More or less coinciding with the Franklin D. Roosevelt administration, there was renewed trust in government and scientific institutions (4), but this too began reversing in the 1950s with the formation of a National Health Federation and later yielding to the far-right conservative John Birch Society. In the 1970s, the Birch Society launched efforts to spectacularize laetrile as a cure for cancer (7). Later, in 2005, Rep. Ron Paul (R-TX-14) sponsored the Health Freedom Protection Act to promote food and dietary supplements, thereby blocking FDA regulatory oversights even on labels making claims to cure or treat illness (8). Thus, both sensationalized cures and nutritional supplements, and their links to a libertarian agenda, generated an American medical freedom movement in its modern form. Its two major tenets included access to nontraditional medications or supplements, and opposition to traditional health practices.

\section{Antivaccines}

Since the founding of the American colonies, antivaccine sentiments have been widely expressed. A devastating smallpox epidemic in Boston in 1721 stimulated the Puritan minister, Rev. Cotton Mather, and his physician, Dr. Zabdiel Boylston, to attempt the relatively new immunization practice of variolation, but they suf- 
fered personal threats and attacks (9). This thread continued into the late 19th century when antivaccination leagues and societies sprang up in New York, New England, and elsewhere, following the formation of an AntiCompulsory Vaccination League in England (10). Dr. William Osler, one of the founders of the Johns Hopkins School of Medicine, recorded his objections to the "anti-vaccinationists" (9).

Indeed, modern 20th century America may represent a rare period when antivaccinationists took a backseat. Dr. Jonas Salk and Dr. Albert Sabin developed their polio vaccines, and this was followed by a string of successes in the development of new vaccines against measles, mumps, rubella, Haemophilus influenzae type B, and rotavirus, among others. Even significant setbacks or catastrophic errors, such as the Cutter incident in which the Salk polio vaccine was not properly inactivated and inadvertently caused paralytic polio, or the exacerbated respiratory illness and possible childhood deaths resulting from a formalin-inactivated respiratory syncytial virus vaccine, or intussusception following oral live rotavirus immunizations, did not derail public enthusiasm and trust in vaccinations.

America's full-throated enthusiasm for vaccines lasted until the early 2000s. The 1998 Lancet publication of a paper from Andrew Wakefield and his colleagues, which asserted that the attenuated measles virus in the measles-mumps-rubella (MMR) vaccine replicated in the colons of children to cause pervasive developmental disorder (autism), ushered in a new era of distrust for vaccine. It also resulted in distrust for the US Health and Human Services agencies promoting vaccinations (9). The early response from the US Centers for Disease Control and Prevention (CDC) was to dismiss growing American discontent for vaccines as a fringe element, until eventually in the 2010s antivaccine sentiment spread across the internet.

The antivaccine movement eventually adopted medical freedom and used it to gain strength and accelerate in size, internet presence, and external funding. Rising out of the American West, antivaccine proponents insisted that only parents could decide vaccine choices and they were prepared to resist government-dictated mandates and requirements for school entry or attendance. In California, the notion of vaccine choice gained strength in the 2010s, causing widespread philosophical exemptions to childhood MMR (measles-mumps-rubella) vaccines and other immunizations. Vaccine exemptions reached critical mass, ultimately culminating in a 2014-15 measles epidemic in Orange County (9). The outbreak prompted state government intervention through the introduction and eventual signing of California Senate Bill 277 that eliminated these exemptions and prevented further epidemics, but it also triggered aggressive opposition (11). Antivaccine health freedom groups harassed members of the legislature and labeled prominent scientists as "pharma shills" (12). They implemented a system of pseudoscience claiming that vaccines were toxic, or that natural immunity acquired from the illness was superior and more durable than vaccine-induced immunity (12).

Health freedom then expanded through newly established antivaccine political action committees (PACs) in Texas and Oklahoma in the Southwest, Oregon in the Pacific Northwest, and Michigan and Ohio in the Midwest (13), while additional antivaccine organizations formed in almost every state. They lobbied state legislatures to promote or protect vaccine exemptions, while working to deliberately cloak or obscure classroom or school-wide disclosures of vaccine exemptions. They also introduced menacing consent forms to portray vaccines as harmful or toxic. The Texans for Vaccine Choice PAC formed in 2015 (14), helping to accelerate personal belief immunization exemptions to a point where today approximately 72,000 Texas schoolchildren miss vaccines required for school entry and attendance. Texas was not alone. By 2018, large numbers of schoolchildren were exempted from vaccinations in at least 15 major urban areas, mostly in Western states (including 3 in Texas) (15), and by 2019 measles erupted with the number of cases in the US exceeding 1000 for the first time since its initial elimination in 2000.

\section{National antivaccine groups and specific targeting}

In parallel to rising health freedom across the western states, national vaccine groups began to form. Their activities included the selection of racial and ethnic groups as targets for antivaccine messages. This first began in 2017 with the Somali immigrant community in Minnesota. Andrew Wakefield and other antivaccine activists participated in town hall meetings to convince the Somali community that the MMR vaccine causes autism (9). Predictably, a large measles outbreak ensued. The following year, the Orthodox Jewish community in New York and New Jersey was flooded with antivaccine messages that compared vaccinations to the Holocaust, as antivaccine ringleaders spoke at rallies in New York and New Jersey (16). Again, a large measles epidemic resulted in dozens of Jewish children in New York requiring hospitalization. By 2019, targeting of African American groups led to rallies in Harlem, New York. Antivaccine activities include comparisons between vaccinations and the infamous midcentury Tuskegee experimentations. Such activities require money and organization, from both private foundations and elements of the health and wellness industry, and are accompanied by promotion of nutritional supplements (17). These links align with the miracle cures of health freedom going back to the 19th century.

\section{COVID-19 health freedom}

In 2020, following the emergence of COVID-19, these same health freedom groups expanded their vaccine protests to social distancing, masks, and other prevention measures (18). They also touted magic cures including hydroxychloroquine. On October 4, 2020, the Great Barrington Declaration (https://gbdeclaration.org/) was posted online, sponsored by the conservative think tank American Institute for Economic Research, to discredit social distancing mandates (19). Deaths from COVID-19 rose precipitously in 2020, particularly in the conservative strongholds in the Southern states during the summer virus surge and in the Great Plains and Midwest in the fall (1). Thus, antivaccine and anti-COVID-19 prevention blended with political extremism on the far right, and even with QAnon and other conspiracy-laden movements. Our recent survey found that former Trump voters represented the most COVID-19 vaccine-hesitant group nationally (20). Also ranked high among those resisting vaccines were African Americans, possibly in response to the specific targeting by antivaccine national groups from the previous year. 
Given the profound loss of life due to health freedom, a new imperative requires national efforts to disentangle antivaccine and anti-COVID-19 prevention activities from far right political agendas. Studies led by the CDC show the effectiveness of mask mandates in reducing hospitalizations (21), and the effectiveness of COVID-19 vaccines have been demonstrated in phase 3 clinical trials (22). Accordingly, COVID-19 prevention will require advocacy for both masks and vaccines, and efforts to counter the antiscience disinformation. With our detailed knowledge and expertise, some of the counteroffensive should originate from the community of scientists and physician-scientists $(23,24)$. It is important that the American people continue to hear from us. For instance, I appear on conservative news outlets to reach individuals at risk from antiscience disinformation, while encouraging conservative leaders to promote COVID-19 prevention strategies and vaccines. But even this is insufficient.

Medical and health freedom and its antiscience tenets represent grave threats to American public health in this new century. We must urgently seek broad and innovative solutions that tap guidance and expertise in multiple areas. For example, we might consider a federal interagency task force across several branches of the US government in order to identify new levers for countering antiscience groups (1). These might extend beyond the standard approaches focused on amplifying provaccination advocacy, instead driving harder to remove nefarious antiscience internet content and other forms of harmful communication. We cannot afford a status quo now thwarting desperate efforts to save lives or reduce COVID-19 long-haul injuries.

The US was the deadliest location worldwide for the COVID-19 epidemic in 2020, and in 2021, we will hold our breath as the new variants emerge and potentially sweep through the country. The high death toll from SARS-2 coronavirus transmission was exacerbated by a medical freedom ideology linked to political extremism. It is vital to US public health and homeland security that we find ways to defuse antiscience organizations, messaging, and health consequences.

Address correspondence to: Peter J. Hotez, One Baylor Plaza, Suite 164a, Houston, Texas 77030, USA. Phone: 713.798.3355; Email:hotez@bcm.edu.

1. Hotez PJ. Anti-science kills: From Soviet embrace of pseudoscience to accelerated attacks on US biomedicine. PLoS Biol. 2021;19(1):e3001068.

2. Rothwell J, Desai S. How misinformation is distorting covid policies and behaviors. Brookings Institution Report. December 22, 2020. Accessed March 2, 2021. https://www.brookings.edu/ research/how-misinformation-is-distortingcovid-policies-and-behaviors/.

3. Lasco G. Medical populism and the COVID-19 pandemic. Glob Public Health. 2020;15(10):1417-1429.

4. Grossman LA. The origins of American health libertarianism. Yale J Health Policy Law Ethics. 2013;13(1):76-134.

5. Flannery MA. The early botanical medical movement as a reflection of life, liberty, and literacy in Jacksonian America. JMed Libr Assoc. 2002;90(4):442-454

6. Petrina S. Medical liberty: drugless healers confront allopathic doctors, 1910-1931. JMed Humanit. 2008;29(4):205-230.

7. Lyons RD. Rightists are linked to laetrile's lobby. The New York Times. July 5, 1977. Accessed March 2, 2021. https://www.nytimes.com/1977/07/05/ archives/rightists-are-linked-to-laetriles-lobbybut-backers-of-purported.html.

8. Health Freedom Protection Act, HR 4282, 109th Congress (2005). Accessed March 2, 2021 https://www.congress.gov/bill/109th-congress/ house-bill/4282.

9. Hotez PJ. Vaccines Did Not Cause Rachel's Autism: My Journey as a Vaccine Scientist, Pediatrician and Autism Dad. Johns Hopkins University Press; 2021.

10. Wolfe RM, Sharp LK. Anti-vaccinationists past and present. BMJ. 2002;325(7361):430-432.
11. Mohanty S, et al. Experiences with medical exemptions after a change in vaccine exemption policy in California. Pediatrics. 2018;142(5):e20181051.

12. Smith TC. Vaccine rejection and hesitancy: a review and call to action. Open Forum Infect Dis. 2017;4(3):ofx146.

13. Lakshmanan R, Sabo J. Lessons from the front line: advocating for vaccines policies at the Texas capitol during turbulent times. J Applied Res Child. 2019;10(2):6.

14. Hotez PJ. Texas and its measles epidemics. PLoS Med. 2016;13(10):e1002153.

15. Olive JK, et al. The state of the antivaccine movement in the United States: a focused examination of nonmedical exemptions in states and counties. PLoS Med. 2018;15(6):e1002578.

16. Einbinder N. The anti-vaxx movement is fueling the measles epidemic by deliberately targeting communities most affected by the disease. Insider. May 21, 2019. Accessed March 2, 2021. https://www.insider. com/anti-vaxx-movement-fueling-measlesepidemic-targetingcommunities-2019-5.

17. Satija N, Sun LH. A major funder of the anti-vaccne movement has made millions selling natural health products. Washington Post. December 20, 2019. Accessed March 2, 2021. https://www. washingtonpost.com/investigations/ 2019/10/15/fdc01078-c29c-11e9-b5e454aa56d5b7ce story.html.

18. Hotez PJ. COVID19 meets the antivaccine movement. Microbes Infect. 2020;22(4):162-164.

19. D'Ambrosio A. Who are the scientists behind the Great Barrington Declaration? MedPage Today. October 19, 2020. Accessed March 2, 2021. https://www.medpagetoday.com/infectiousdisease/covid19/89204.

20. Callaghan T, et al. Correlates and disparities of intention to vaccinate against COVID-19. Soc Sci Med. 2020;272:113638.

21. Joo H, et al. Decline in COVID-19 hospitalization growth rates associated with statewide mask mandates - 10 States, March-October 2020. MMWR Morb Mortal Wkly Rep. 2021;70(6):212-216

22. Polack FP, et al. Safety and efficacy of the BNT162b2 mRNA Covid-19 vaccine. $N$ Engl J Med. 2020;383(27):2603-2615.

23. Hotez PJ. The physician-scientist: defending vaccines and combating antiscience. JClin Invest. 2019;129(6):2169-2171.

24. Hotez PJ. Combating antiscience: are we preparing for the 2020s? PLoS Biol. 2020;18(3):e3000683. 